\title{
Penerapan Jaringan Saraf Tiruan Dalam Memprediksi Indikator Utama Ekonomi Dunia
}

\author{
Alan Boy Sandy Damanik ${ }^{1}$, Agung Bimantoro ${ }^{2}$ \\ 1,2,3Program Studi Teknik Informatika, STIKOM Tunas Bangsa Pematangsiantar \\ Jln. Jendral Sudirman Blok A No. 1-3, Kota Pematangsiantar, 21111, Indonesia \\ alanboysandy08@gmail.com ${ }^{1}$, agungbimantara038@gmail.com²
}

\begin{abstract}
Economics is one of the most important aspects in the world. Economics greatly determines the progress and development of a country. However, there are still many countries with low economic levels. Therefore the aim of this study is to predict and determine the level of the main indicators of the world economy as one of the anticipatory steps to further increase the level of the country's economy. World Economic Indicator Data to be used is sourced from Bloomberg and Bank Indonesia. To find out further developments, it is necessary to research the existing data. The algorithm used is Backpropagatian Neural Network. Data analysis was carried out using artificial neural network method using Matlab R2011b software. The study uses 5 architectural models. The best network architecture produced is 3-43-1 with an accuracy rate of 86\% and the Mean Squared Error (MSE) value is 1.336593 ..
\end{abstract}

Keywords: Application, ANN, Indicator, Economy, World

\begin{abstract}
Abstrak
Ekonomi merupakan salah satu aspek terpenting di Dunia. Ekonomi sangat menentukan kemajuan dan perkembangan suatu negara. Akan tetapi masih banyak negara-negara yang tingkat perekonomiannya rendah. Oleh karena itu tujuan dari penelitian ini adalah untuk memprediksi dan menentukan tingkat Indikator utama ekonomi dunia sebagai salah satu langkah antisipasi untuk semakin meningkatkan tingkat perekonomian negara. Data Indikator Ekonomi Dunia yang akan digunakan bersumber dari Bloomberg dan Bank Indonesia. Untuk mengetahui perkembangan selanjutnya perlu di lakukan penelitian terhadap data yang ada. Algoritma yang digunakan adalah Jaringan Saraf Tiruan Backpropagatian. Penganalisaan data dilakukan dengan metode jaringan saraf tiruan menggunakan software Matlab R2011b. Penelitian menggunakan 5 model arsitektur. Arsitektur jaringan terbaik yang dihasilkan adalah 3-43-1 dengan tingkat akurasi 86\% dan nilai Mean Squared Error (MSE) adalah 1,336593.
\end{abstract}

Kata Kunci: Penerapan, JST, Indikator, Ekonomi, Dunia

\section{PENDAHULUAN}

Ekonomi merupakan salah satu aspek terpenting di suatu negara. Setiap negara pasti ingin perekonomian di negaranya selalu bertumbuh. Pertumbuhan ekonomi merupakan suatu tanda bahwa kondisi perekonomian suatu negara sedang menuju keadaan yang lebih baik [1]. Pertumbuhan ekonomi sebagai sebuah proses peningkatan output dari waktu ke waktu menjadi indikator penting untuk mengukur keberhasilan pembangunan suatu negara [2]. Salah satu indikator ekonomi makro yang digunakan untuk melihat/mengukur stabilitas perekonomian suatu negara adalah inflasi. Perubahan dalam indikator ini akan berdampak terhadap dinamika pertumbuhan ekonomi [3].

Salah satu alasan utamanya adalah kemajuan dalam teknologi informasi yang sampai batas tertentu, memperbesar gelombang krisis dan mempercepat penyebarannya ke daerah atau negara lain [4]. Sistem perkonomian oleh suatu 
negara atau pemerintah digunakan untuk memecahkan berbagai macam permasalahan yang berkaitan dengan ekonomi yang dialaminya, tentunya agar permasalahan-permasalahan yang berkaitan dengan ekonomi itu dapat teratasi dan terselesaikan, justru jangan sampai dengan ada dan munculnya suatu sistem ekonomi malah menambah atau bahkan memperparah masalah ekonomi suatu negara yang semakin membebani [5][6]. Salah satu faktor terbesar sampai saat ini yang mempengaruhi indikator utama ekonomi dunia ialah Ideks-naik dolar menguat dan itu di buktikan dari perkembangan dan pertumbuhan nilai dolarr yang semangkin kuat. Hal itu di buktikan pada tahun 2014 Indeks-naik dolar itu sampai 81,5 \% dan sampai pada tahun 2016. Indeks-naik dolar mencapai angka 96,9\%. Bisa dilihat dalam tabel berikut pertumbuhan Ekonomi dari tahun 20142016 :

Tabel 1. Indikator Utama Ekonomi Dunia

\begin{tabular}{lrrrr}
\hline \multicolumn{1}{c}{ Komponen } & $\mathbf{2 0 1 3}$ & $\mathbf{2 0 1 4}$ & $\mathbf{2 0 1 5}$ & $\mathbf{2 0 1 6}$ \\
\hline Pertumbuhan Ekonomi Dunia (\%) & 3,3 & 3,4 & 3,2 & 3,1 \\
Pertumbuhan Volume Perdagangan Dunia (\%) & 2,2 & 2,7 & 2 & 1 \\
Harga Minyak Dunia (dolar AS/barel) & 98 & 92,9 & 48,8 & 43,5 \\
Harga Minas (dolar AS/barel) & 108,4 & 98,7 & 49 & 41 \\
Indeks Harga Komoditas Ekspor Nonmigas & $-9,8$ & $-4,3$ & -15 & 5,4 \\
Indonesia (\%) & 81,5 & 82,6 & 96,3 & 96,9 \\
Rata-Rata DXY (Indeks-naik dolar menguat) & 14,1 & 14,1 & 16,6 & 15,8 \\
Rata-Rata VIX (indeks-naik volatilitas meningkat)
\end{tabular}

Tabel 1 menunjukkan beberapa hal besar yang mempengaruhi pertumbuhan dan perkembangan indikator ekonomi dunia. Hal itu bisa menjadi dampak baik dan dampak yang buruk terhadap perkembangan ekonomi tersebut.

Salah satu keuntungan dari prediksi indikator utama ekonomi dunia adalah pemerintah dapat melihat perkembangan dan pertumbuhan perekonomian dari tahun ke tahun. erkembangan ekonomi dapat berpengaruh besar terhadap beberapa negara yang ada di dunia, dampak yang berpengaruh juga bermacam macam ada yang berpengaruh baik dan ada yang berpengaruh buruk. Hal itu memacu setiap negara harus mampu mengikuti perkembangan ekonomi dunia. Akan tetapi dampak buruk bisa menjadi sangat buruk terhadap negara negar yang sedang berkembang, karena dapat menjadikan negara tersebut menjadi krisis ekonomi yang besar. Maka negara negara harus bisa memprediksi bagaiman kelanjutan perkembangan ekonomi dunia dan bagai mana pertumbuhan dari tahun ke tahun. Salah satu teknik yang baik digunakan untuk prediksi adalah jaringan saraf tiruan backpropagation karena algoritma backpropagation memungkinkan untuk menghindari kesulitan yang dijelaskan menggunakan aturan belajar yang mirip dengan plastisitas lonjakan waktu yang tergantung pada sinapsis [7][8][9][10].

Pada penelitian sebelumnya, [11] melakukan penelitian untuk meramalkan kecepatan angin. Jaringan tersebut dapat digunakan dengan baik untuk prakiraan dengan nilai MSE prakiraan kecepatan angin sebesar 0,0086 dan nilai MSE prakiraan curah hujan sebesar 0,004846. Kekurangan dari penelitian ini adalah penggunaan parameter yang terlalu besar, yakni 0,9. [12] Melakukan penelitian 
untuk memprediksi nilai Indeks Harga Konsumen sektor bahan makanan dengan menggunakan metode backpropagation dan conjugate gradient fletcher reeves. Hasil prediksi sebesar $75 \%$ dan $67 \%$. Kekurangan dari penelitian ini adalah akurasi prediksi yang tidak terlalu besar. [13] Melakukan penelitian untuk memprediksi kepailitan Bank Umum di Indonesia menggunakan Algoritma Backpropagation dengan hasil akurasi sebesar 86,11\%. [14] Melakukan penelitian untuk memprediksi nilai Indeks Harga Konsumen sektor Kesehatan dengan menggunakan metode backpropagation, dari penelitian ini learning yang digunakan sebesar 0,5 dengan hasil akurasi 92\%. Berdasarkan penelitian diatas maka penulis melakukan penelitian untuk memprediksi indikator utama ekonomi dunia menggunakan algoritma Backpropagation dengan menggunakan learning rate $0,001-0,01$.

\section{METODE PENELITIAN}

\subsection{Kerangka Kerja Penelitian}

Kerangka kerja penelitian yang digunakan dalam menyelesaikan masalah penelitian ini dapat dilihat pada gambar 1 berikut [29][30].

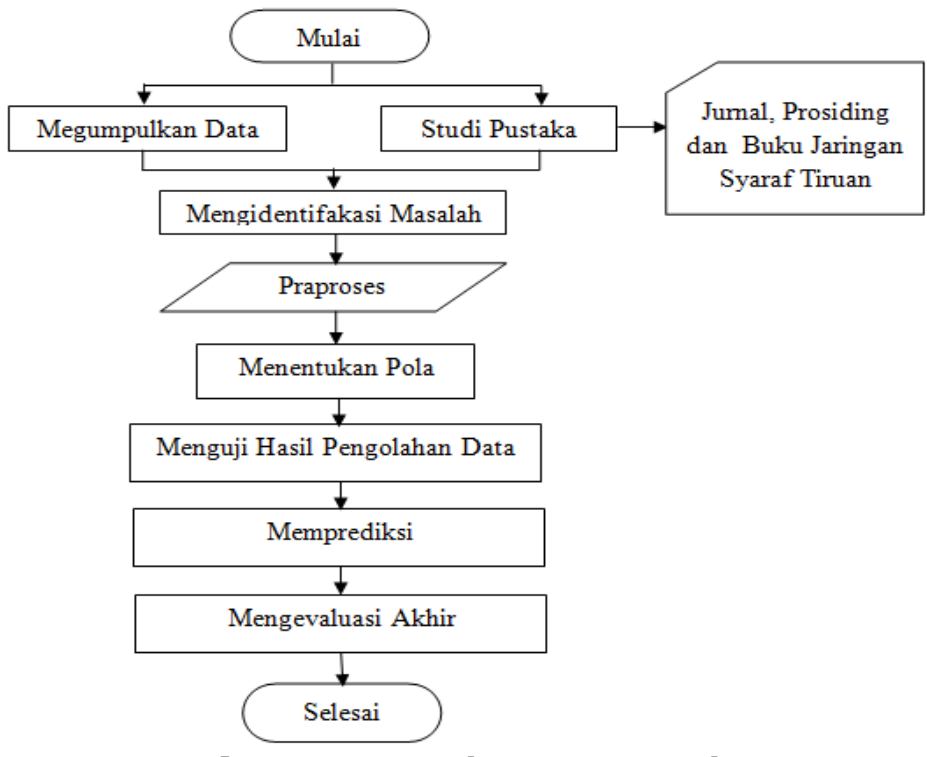

Gambar 1. Kerangka Kerja Penelitian

1. Mengumpulkan Data

Sejauh ini data yang diperoleh berdasarkan Kemenkoinfo yang di dapat secara Random atau secara acak.

2. Studi Pustaka

Studi pustaka merupakan salah satu langkah awal dalam suatu penelitian yang di lakukan, yang di gunakan untuk melengkapi pengetahuan dan teori teori dasar yang di gunakan di dalam penelitian ini.

3. Mengidentifikasi Masalah

Masalah pada tahap ini dapat di identifikasi setelah data-data semua terkumpul dan lengkap,kemudian di dapat hasil yang sesuai untuk selanjutnya di lakukan proses di dalam konversi data yang di sesuaikan dengan bobot yang telah di tentukan. 


\section{Praproses}

Praproses ini merupakan pengeditan atau perubahan terhadap beberapa tipe data yang terdapat di dalam dataset yang bertujuan untuk mempermudah pemahaman beberapa record dan juga untuk menyeleksi dan memperhatikan konsistensi data, redudant data dan missing valuenya.

5. Menentukan Model

Tahap ini adalah hasil dari beberapa tahap dari jaringan saraf tiruan dengan metode Backpropagation untuk menentukan polanya.

6. Memprediksi

Pada model ini prediksi di lakukan untuk mendapatkan jumlah dari perbandingan jumlah dengan model Jaringan Saraf Tiruan dengan metode backpropagation yang akurat.

7. Mengevaluasi Akhir

Model ini untuk mengatahui apkah hasil ari sistem testing pengolahan data apakah sesuai denganyang di harapkan.

8. Menguji Hasil Pengolahan Data

Setelah hasil dan menentukan model selesai, maka selanjutnya di lakukan tes uji coba dengan menggunakan aplikasi software Matlab R2011b.

\subsection{Jaringan Saraf Tiruan Backpropagation}

Jaringan saraf tiruan merupakan fungsi aproksimasi umum yang memiliki keakuratan dalam proses klasifikasi, dan merupaka model nonlinier sehingga menjadi model yang sangat fleksibel dalam hubungan pemodelan yang sangat kompleks [15][16][17]. Jaringan Saraf Tiruan dapat digunakan untuk memodelkan hubungan yang kompleks antara nilai masukan dan keluaran untuk menemukan pola-pola dalam data. Karena terinspirasi oleh model kerja jaringan saraf biologis otak, Jaringan Saraf Tiruan memproses sejumlah besar informasi secara paralel dan terdistribusi [18][19][20]. Jaringan Saraf Tiruan Backpropagation, merupakan salah satu jenis Jaringan Saraf Tiruan (JST) feed forward dengan proses belajar dibimbing (supervised learning), ber- fungsi memilah-milah citra warna yang terdapat dalam image [21][22][23].

\subsection{Ekonomi}

Ekonomi merupakan salah satu faktor penentu kemajuan, kesejahteraan dan yang paling berpengaruh terhadap kelangsungan perkembangan dan pertumbuhan Negara. Pertumbuhan ekonomi berpengaruh signifikan terhadap penurunan jumlah penduduk miskin walaupun dengan magnitude yang relatif kecil, seperti inflasi, populasi penduduk, share sektor pertanian, dan sektor industri [24][25].

\subsection{Prediksi}

Prediksi merupakan sesuatu yang terkait dengan tujuan dan merupakan hasil yang di ramalkan di masa yang akan datang [26][27][28]. 


\subsection{Data Yang Digunakan}

Data yang digunakan adalah data Indikator Ekonomi Dunia dari Tahun 20132016. Data ini akan dibagi menjadi 2 bagian, yaitu data training dan data testing [31]. Data yang digunakan sebagai data Training adalah data tahun 2013-2015 dengan target tahun 2016, sementara data yang di gunakan untuk Testing adalah tahun 2014-2016 dengan target tahun 2017.

\subsection{Normalisasi Data}

Sebelum diproses, data dinormalisasi terlebih dahulu dengan menggunakan fungsi Sigmoid (tidak pernah mencapai 0 ataupun 1), maka transformasi data dilakukan pada interval yang lebih kecil yaitu [0.1;0.9], ditunjukkan dengan persamaan (1) [32][33].

$x^{\prime}=\frac{0.8(x-a)}{b-a}+0.1$

Keterangan :

$x^{\prime}=$ Normalisasi data

$x=$ Data yang akan dinormalisasi

$a=$ Data terendah

$b=$ Data tertinggi

Pada tabel 2 dan 3 dapat dilihat data training dan data testing yang telah dinormalisasi menggunakan rumus persamaan (1).

Tabel 2. Normalisasi Data Training Tahun 2013-2015 / Target Tahun 2015

\begin{tabular}{lcccc}
\hline \multicolumn{1}{c}{ Komponen } & $\mathbf{2 0 1 3}$ & $\mathbf{2 0 1 4}$ & $\mathbf{2 0 1 5}$ & Target \\
& & & & \\
\hline Pertumbuhan Ekonomi Dunia (\%) & 0,21864 & 0,21929 & 0,21799 & 0,21799 \\
Pertumbuhan Volume Perdagangan Dunia (\%) & 0,21151 & 0,21475 & 0,21021 & 0,21021 \\
Harga Minyak Dunia (dolar AS/barel) & 0,83258 & 0,79951 & 0,51361 & 0,51361 \\
Harga Minas (dolar AS/barel) & 0,90000 & 0,83712 & 0,51491 & 0,51491 \\
Indeks Harga Komoditas Ekspor Nonmigas Indonesia (\%) & 0,13371 & 0,16937 & 0,10000 & 0,10000 \\
Rata-Rata DXY (Indeks-naik dolar menguat) & 0,72561 & 0,73274 & 0,82156 & 0,82156 \\
Rata-Rata VIX (indeks-naik volatilitas meningkat) & 0,28865 & 0,28865 & 0,30486 & 0,30486 \\
\hline
\end{tabular}

Tabel 3. Normalisasi Data Testing Tahun 2014-2016 / Target Tahun 2016

\begin{tabular}{lrrrr}
\hline \multicolumn{1}{c}{ Komponen } & $\mathbf{2 0 1 4}$ & $\mathbf{2 0 1 5}$ & $\mathbf{2 0 1 6}$ & Target \\
& & & & \\
\hline Pertumbuhan Ekonomi Dunia (\%) & 0,22946 & 0,22806 & 0,22735 & 0,22735 \\
Pertumbuhan Volume Perdagangan Dunia (\%) & 0,22454 & 0,21961 & 0,21258 & 0,21258 \\
Harga Minyak Dunia (dolar AS/barel) & 0,85919 & 0,54890 & 0,51161 & 0,51161 \\
Harga Minas (dolar AS/barel) & 0,90000 & 0,55031 & 0,49402 & 0,49402 \\
Indeks Harga Komoditas Ekspor Nonmigas Indonesia (\%) & 0,17529 & 0,10000 & 0,24354 & 0,24354 \\
Rata-Rata DXY (Indeks-naik dolar menguat) & 0,78672 & 0,88311 & 0,88734 & 0,88734 \\
Rata-Rata VIX (indeks-naik volatilitas meningkat) & 0,30475 & 0,32234 & 0,31671 & 0,31671 \\
\hline
\end{tabular}

\section{HASII DAN PEMBAHASAN}

Penelitian ini menggunakan 5 arsitektur. Arsitektur tersebut anrara lain : 326-1, 3-29-1, 3-33-1, 3-43-1, 3-80-1. Dan diantara 5 arsitektur tersebut yang paling 
tertinggi (terbaik) adalah 3-43-1 dengan tingkat akurasi mencapai 86\% dan nilai epoch 1058 iterasi.

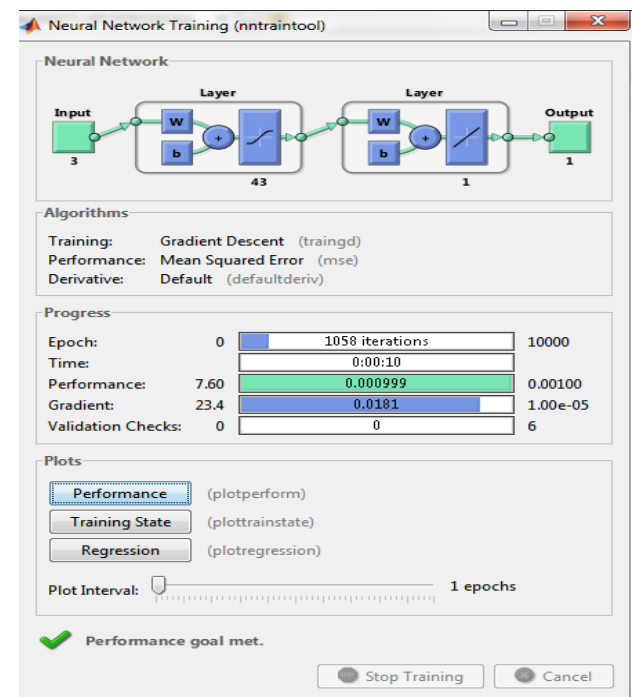

Gambar 2. Data Training Dengan Model Arsitektur 3-43-1

Pada gambar 2 dapat dijelaskan bahwa data training terbaik dengan arsitektur 343-1 menggunakan aplikasi Matlab 2011b menghasilkan epoch 1058 iterasi dengan waktu 0:00:10 detik. 3 adalah data input, 43 merupakan hidden layer sedangkan 1 adalah output atau hasil.

Pada tabel 3 dapat dilihat hasil akurasi dan tingkat MSE dari model arsitektur terbaik, yakni 3-43-1. Tabel 3 ini dibuat dan dihitung dengan menggunakan Microsoft Excel. Berdasarkan tabel 3, error = diperoleh dari Target-Output, SSE = diperoleh dari E3 ${ }^{\wedge} 2$, Total = Jumlah SSE yang dihasilkan dari pola 1 ke pola 6 , Hasil = Jika nilai kesalahan dalam pengujian data $<=0.01$ maka hasilnya benar (1). Jika tidak maka salah (0). Akurasi = diperoleh dari jumlah hasil yang benar pada ((pola / 7) * 100), menghasilkan 86\%, Margin Error = diperoleh dari jumlah hasil yang salah pada ((pola / 7) * 100) atau diperoleh dari jumlah akurasi maksimum $(100 \%)$ dikurangi akurasi yang dihasilkan, menghasilkan 14\%. MSE = Diperoleh dari Total SSE / 7 (jumlah pola). Pada kolom hasil, angka $1=$ Benar sedangkan $0=$ Salah.

Tabel 3. Arsitektur Terbaik dengan Model 5-18-1

Keterangan :

\begin{tabular}{cccccc}
\hline No & Target & Output & Error & SSE & Hasil \\
\hline 1 & 0,22735 & 0,24180 & $-0,01445$ & 0,00021 & 1 \\
2 & 0,21258 & 0,28120 & $-0,06862$ & 0,00471 & 1 \\
3 & 0,51161 & 2,61110 & $-2,09949$ & 4,40786 & 1 \\
4 & 0,49402 & 2,64990 & $-2,15588$ & 4,64782 & 1 \\
5 & 0,24354 & 0,53230 & $-0,28876$ & 0,08338 & 1 \\
6 & 0,88734 & 0,43060 & 0,45674 & 0,20861 & 0 \\
7 & 0,31671 & 0,37640 & $-0,05969$ & 0,00356 & 1 \\
\hline & & & Total & 9,35615 & \multirow{2}{*}{$86 \%$} \\
\cline { 3 - 4 } & & & MSE & 1,336593 & \\
\cline { 3 - 4 } & & & &
\end{tabular}

$1=$ Benar $\quad 0=$ Salah 
Pada tabel 4 dapat dilihat perbandingan dari 5 model arsitektur jaringan yang digunakan. Dari ke 5 model arsitektur ini, tingkat Epoch dan waktu diperoleh dengan menggunakan aplikasi Matlab 2011b, sedangkan MSE dan Akurasi dari masing-masing model arsitektur diperoleh dengan menggunakan perhitungan pada Microsoft Excel. Sebenarnya ada 2 model arsitektur yang menghasilkan tingkat akurasi yang sama sebesar 86\%, yakni 3-26-1 dan 3-43-1. Hanya saja model arsitektur 3-43-1 lebih rendah epoch, waktu dan MSE training nya. Sehingga penulis berkesimpulan dari ke 5 model arsitektur ini diperoleh model arsitektur terbaik menggunakan 3-43-1.

Tabel 4. Perbandingan Model Arsitektur yang Digunakan

\begin{tabular}{cccccc}
\hline No & Arsitektur & Epoch & Waktu & MSE & Akurasi \\
\hline 1 & $3-26-1$ & 3146 & $0: 00: 22$ & 0,359344 & $86 \%$ \\
2 & $3-29-1$ & 451 & $0: 00: 04$ & 1,452931 & $43 \%$ \\
3 & $3-33-1$ & 1687 & $0: 00: 12$ & 0,672248 & $71 \%$ \\
4 & $3-43-1$ & 1058 & $0: 00: 08$ & 1,336593 & $86 \%$ \\
5 & $3-80-1$ & 319 & $0: 00: 04$ & 1,94783 & $43 \%$ \\
\hline
\end{tabular}

Pada tabel 4 dapat dilihat hasil prediksi dari Indikator Utama Ekonomi Dunia untuk 3 tahun kedepan, yakni tahun 2017-2019. Adapun hasil ini diperoleh dari perhitungan dengan model arsitektrur terbaik (3-43-1) menggunakan aplikasi Matlab 2011b dan Microsoft Excel, sama seperti pada pembahasan sebelumnya.

Tabel 5. Hasil Prediksi JST Backpropagation (Tahun 2017-2019)

\begin{tabular}{lrrr}
\hline \multicolumn{1}{c}{ Komponen } & $\mathbf{2 0 1 7}$ & $\mathbf{2 0 1 8}$ & $\mathbf{2 0 1 9}$ \\
\hline Pertumbuhan Ekonomi Dunia (\%) & 13,9 & 36,7 & 57,9 \\
Pertumbuhan Volume Perdagangan Dunia (\%) & 12,1 & 28,8 & 47,4 \\
Harga Minyak Dunia (dolar AS/barel) & 56,8 & 66,7 & 73,4 \\
Harga Minas (dolar AS/barel) & 42 & 52,5 & 63,7 \\
Indeks Harga Komoditas Ekspor Nonmigas Indonesia (\%) & 20,7 & 34,1 & 46,6 \\
Rata-Rata DXY (Indeks-naik dolar menguat) & 95,1 & 93,7 & 91,5 \\
Rata-Rata VIX (indeks-naik volatilitas meningkat) & 28,8 & 49,9 & 61,6 \\
\hline
\end{tabular}

\section{SIMPULAN}

Kesimpulan yang dapat diambil dari penulisan paper ini antara lain, bahwa model arsitektur terbaik dari ke 5 model arsitektur yang digunakan adalah 3-43-1, yang menghasilkan akurasi prediksi sebesar 86\%. Berdasarkan perbandingan antara hasil prediksi dengan data awal pada komponen indikator utama ekonomi dunia, terdapat kenaikan yang cukup signifikan hampir di semua komponen, antara lain pada komponen Pertumbuhan Ekonomi Dunia (\%),Pertumbuhan Volume Perdagangan Dunia (\%),Rata-Rata DXY (Indeks-naik dolar menguat) dan Rata-Rata VIX (indeks-naik volatilitas meningkat). Sedangkan untuk komponen Harga Minyak Dunia (dolar AS/barel), Harga Minas (dolar AS/barel) dan Indeks Harga Komoditas Ekspor Nonmigas Indonesia (\%) cenderung tidak stabil (naik turun) 


\section{DAFTAR PUSTAKA}

[1] T. Lesmana, "Perkembangan Indikator Ekonomi Dan Kemakmuran Indonesia Dibandingkan Dengan 6 Negara Tetangga Periode 2005-2012," Binus Business Review, vol. 5, no. 1, pp. 101-111, 2014.

[2] A. Ma'ruf and L. Wihastuti, "Pertumbuhan Ekonomi Indonesia: Determinan dan Prospeknya," Jurnal Ekonomi \& Studi Pembangunan, vol. 9, no. April, pp. 44-55, 2012.

[3] E. D. Silvia, Y. Wardi, and H. Aimon, "Analisis Pertumbuhan Ekonomi, Investasi, Dan Inflasi Di Indonesia," Jurnal Kajian Ekonomi, vol. 1, no. 2, pp. 224-243, 2013.

[4] A. F. Raz, A. Timur, T. P. K. Indra, D. K. Artikasih, and S. Citra, "Krisis Keuangan Global Dan Pertumbuhan Ekonomi: Analisa Dari Perekonomian Asia Timur," Buletin Ekonomi dan Moneter dan Perbankan, pp. 37-56, 2012.

[5] S. Perekonomian and N. Di Dunia, "Sistem Perekonomian Negara-Negara Di Dunia," JURNAL AKUNTANSI DAN PAJAK, vol. 16, no. 2, pp. 20-29, 2016.

[6] Y. Andriani, H. Silitonga, and A. Wanto, "Analisis Jaringan Saraf Tiruan untuk prediksi volume ekspor dan impor migas di Indonesia," Register - Jurnal Ilmiah Teknologi Sistem Informasi, vol. 4, no. 1, pp. 30-40, 2018.

[7] A. Wanto, "Optimasi Prediksi Dengan Algoritma Backpropagation Dan Conjugate Gradient Beale-Powell Restarts," Jurnal Teknologi dan Sistem Informasi, vol. 3, no. 3, pp. 370-380, Jan. 2018.

[8] A. Wanto, A. P. Windarto, D. Hartama, and I. Parlina, "Use of Binary Sigmoid Function And Linear Identity In Artificial Neural Networks For Forecasting Population Density," International Journal Of Information System \& Technology, vol. 1, no. 1, pp. 43-54, 2017.

[9] A. P. Windarto, L. S. Dewi, and D. Hartama, "Implementation of Artificial Intelligence in Predicting the Value of Indonesian Oil and Gas Exports With BP Algorithm," International Journal of Recent Trends in Engineering \& Research (IJRTER), vol. 3, no. 10, pp. 1-12, 2017.

[10] M. Fauzan et al., "Epoch Analysis And Accuracy 3 ANN Algorithm Using Consumer Price Index Data In Indonesia," International Conference of Computer, Environment, Agriculture, Social Science, Health Science, Engineering and Technology (3rd ICEST). pp. 1-7, 2018.

[11] R. J. Yuniar, D. Rahadi, and S. Onny, "Perbaikan Metode Prakiraan Cuaca Bandara Abdulrahman Saleh Dengan Algoritma Neural Network Backpropagation," Jurnal EECCIS, vol. 7, no. 1, pp. 65-70, 2013.

[12] A. Wanto, M. Zarlis, Sawaluddin, and D. Hartama, "Analysis of Artificial Neural Network Backpropagation Using Conjugate Gradient Fletcher Reeves in the Predicting Process," Journal of Physics: Conference Series, vol. 930, no. 1, pp. 1-7, 2017.

[13] A. S. Malaka and Hartojo, "Model Prediksi Kepailitan Bank Umum Di Indonesia Menggunakan Algoritma Backpropagation," Jurnal Ilmu Manajemen, vol. 2, no. 4, pp. 1714-1724, 2014.

[14] A. Wanto and A. P. Windarto, "Analisis Prediksi Indeks Harga Konsumen Berdasarkan Kelompok Kesehatan Dengan Menggunakan Metode Backpropagation," Jurnal \& Penelitian Teknik Informatika Sinkron, vol. 2, no. 2, pp. 37-43, Oct. 2017. 
[15] A. A. Kasim and A. Harjoko, "Klasifikasi Citra Batik Menggunakan Jaringan Saraf Tiruan Berdasarkan Gray Level Co- Occurrence Matrices ( GLCM )," in Seminar Nasional Aplikasi Teknologi Informasi (SNATI) Yogyakarta, 21 Juni 2014, 2014, pp. 7-13.

[16] A. Wanto et al., "Levenberg-Marquardt Algorithm Combined with Bipolar Sigmoid Function to Measure Open Unemployment Rate in Indonesia," in 3rd International Conference of Computer, Environment, Agriculture, Social Science, Health Science, Engineering and Technology, 2018, pp. 1-7.

[17] E. Hartato, D. Sitorus, and A. Wanto, "Analisis Jaringan Saraf Tiruan Untuk Prediksi Luas Panen Biofarmaka di Indonesia," Jurnal semanTIK, vol. 4, no. 1, pp. 49-56, 2018.

[18] M. C. C. Utomo, W. F. Mahmudy, and S. Anam, "Kombinasi Logika Fuzzy dan Jaringan Saraf Tiruan untuk Prakiraan Curah Hujan Timeseries di Area Puspo - Jawa Timur," Jurnal Teknologi Informasi dan Ilmu Komputer, vol. 4, no. 3, pp. 160-167, 2017.

[19] Sumijan, A. P. Windarto, A. Muhammad, and Budiharjo, "Implementation of Neural Networks in Predicting the Understanding Level of Students Subject," International Journal of Software Engineering and Its Applications, vol. 10, no. 10, pp. 189-204, 2016.

[20] A. P. Windarto, D. Hartama, and N. Dalimunthe, "Model Arsitektur Backpropogation Dalam Memprediksi Faktor Tunggakan Uang Kuliah (Studi Kasus AMIK Tunas Bangsa)," in Seminar Nasional Multidisiplin, 2017, pp. 19.

[21] A. Wanto et al., "Analysis Of Standard Gradient Descent With GD Momentum And Adaptive LR For SPR Prediction," in International Conference of Computer, Environment, Agriculture, Social Science, Health Science, Engineering and Technology (3rd ICEST), 2018, pp. 1-9.

[22] J. Adler, "Image Processing Sayatan Tipis Batuan Gamping dengan Jaringan Saraf Tiruan (JST) Menggunakan Matlab dan Linux (Studi Kasus: Rajamandala-Padalarang)," Teknik Komputer, vol. Volume 12, 2014.

[23] Solikhun, A. P. Windarto, Handrizal, and M.Fauzan, "Jaringan Saraf Tiruan Dalam Memprediksi Sukuk Negara Ritel Berdasarkan Kelompok Profesi Dengan Backpropagation Dalam Mendorong Laju Pertumbuhan Ekonomi," Kumpulan jurnaL Ilmu Komputer (KLIK), vol. 4, no. 2, pp. 184-197, 2017.

[24] H. Siregar and D. Wahyuni, "Dampak Pertumbuhan Ekonomi Terhadap Penurunan Jumlah Penduduk Miskin," Economics development, no. pertumbuhan ekonomi dan penduduk miskin, pp. 1-28, 2007.

[25] J. R. Saragih, M. Billy, S. Saragih, and A. Wanto, "Analisis Algoritma Backpropagation Dalam Prediksi Nilai Ekspor (Juta USD)," Jurnal Pendidikan Teknologi dan Kejuruan, vol. 15, no. 2, pp. 254-264, 2018.

[26] A. Wanto, "Penerapan Jaringan Saraf Tiruan Dalam Memprediksi Jumlah Kemiskinan Pada Kabupaten/Kota Di Provinsi Riau," Kumpulan jurnaL Ilmu Komputer (KLIK), vol. 5, no. 1, pp. 61-74, 2018.

[27] S. Putra Siregar and A. Wanto, "Analysis Accuracy of Artificial Neural Network Using Backpropagation Algorithm In Predicting Process (Forecasting)," International Journal of Information System \& Technology, vol. 1, no. 1, pp. 34-42, 2017. 
[28] M. A. P. Hutabarat, M. Julham, and A. Wanto, "Penerapan Algoritma Backpropagation Dalam Memprediksi Produksi Tanaman Padi Sawah Menurut Kabupaten/Kota di Sumatera Utara," Jurnal semanTIK, vol. 4, no. 1, pp. 77-86, 2018.

[29] J. Wahyuni, Y. W. Paranthy, and A. Wanto, "Analisis Jaringan Saraf Dalam Estimasi Tingkat Pengangguran Terbuka Penduduk Sumatera Utara," Jurnal Infomedia, vol. 3, no. 1, pp. 18-24, 2018.

[30] I. S. Purba and A. Wanto, "Prediksi Jumlah Nilai Impor Sumatera Utara Menurut Negara Asal Menggunakan Algoritma Backpropagation," Jurnal Teknologi Informasi Techno, vol. 17, no. 3, pp. 302-311, 2018.

[31] R. E. Pranata, S. P. Sinaga, and A. Wanto, "Estimasi Wisatawan Mancanegara Yang Datang ke Sumatera Utara Menggunakan Jaringan Saraf," Jurnal semanTIK, vol. 4, no. 1, pp. 97-102, 2018.

[32] A. P. Windarto, "Implementasi JST Dalam Menentukan Kelayakan Nasabah Pinjaman Kur Pada Bank Mandiri Mikro Serbelawan Dengan Metode Backpropagation," Jurnal Sains Komputer \& Informatika (J-SAKTI), vol. 1, no. 1, pp. 12-23, 2017.

[33] A. A. Fardhani, D. Insani, N. Simanjuntak, and A. Wanto, "Prediksi Harga Eceran Beras Di Pasar Tradisional Di 33 Kota Di Indonesia Menggunakan Algoritma Backpropagation," Jurnal Infomedia, vol. 3, no. 1, pp. 25-30, 2018. 